УДК. 796/799
https://doi.org/10.36906/FKS-2021/79

Петрунина С.В.

ORCID: 0000-0002-6174-2185, канд. пед. наук

Пензенский государственный университет,

г. Пенза, Россия

\title{
ФОРМИРОВАНИЕ МОТИВАЦИИ К ЗАНЯТИЯМ ПО АДАПТИВНОМУ ПЛАВАНИЮ ЛИЦ С ДЦП И НАРУШЕНИЯМИ ПСИХИЧЕСКОГО РАЗВИТИЯ
}

Аннотация. В статье представлены результаты исследования в процессе обучения адаптивному плаванию, показано формирование мотивации к занятиям адаптивного плавания людей с ДЦП и с нарушениями психического развития.

Ключевые слова: поражения ОДА, детский церебральный паралич, нарушения психического развития, коррекция двигательных действий в водной среде, индивидуальная экспериментальная методика, адаптивное плавание.

Petrunina S.V. ORCID: 0000-0002-6174-2185, Ph.D.

Penza State University,

Penza, Russia

\section{FORMATION OF MOTIVATION FOR ADAPTIVE SWIMMING CLASSES FOR PEOPLE WITH INJURIES OF THE MUSCULOSKELETAL SYSTEM AND PEOPLE WITH MENTAL DEVELOPMENT DISORDERS}

Annotation. The article presents the results of a study in the process of learning adaptive swimming, shows the formation of motivation for adaptive swimming classes for people with cerebral palsy and with mental development disorders.

Keywords: musculoskeletal system lesion, delayed mental development, correction of motor actions in the aquatic environment, individual experimental method, adaptive swimming.

На базе ФОК «Дельфин» нами проводятся учебно-тренировочные занятия по адаптивному плаванию для контингента с различными поражениями ОДА и нарушениями, и расстройствами психического развития и интеллекта. Занимающиеся, в количестве 10 человек, были разделены на две равномерные группы по 5 человек в каждой. В первую группу входили лица с поражениями ОДА, а в вторую группу составляли лица с нарушениями психического развития и интеллекта. Учебно-тренировочные занятия по адаптивному плаванию проводятся 4 раза в неделю, по 60 минут каждое. Перед каждым занятием проводился инструктаж о правилах поведения и безопасности на занятиях по адаптивному плаванию. В связи со специфичностью нашего контингента на занятиях использовалась индивидуально-групповая форма. Для определения достоверности данных внутри групп применялся «критерий Манна-Уитни» [3; 4].

Учебно-тренировочные занятия строились по адаптивной методики, которая была свойственна заболеваниям данной категории, в индивидуальной форме. В первой группе, в которую входили лица с поражениями ОДА, больше времени отводилось на разгрузку опорнодвигательного аппарата, на принятие горизонтального положения, и проплывание отрезков с работой ног и рук. Во второй группе, в которую входили лица с нарушениями психического 
развития и интеллектуальной сферы, основной задачей было настроить занимающихся на правильное выполнение задания, а также сконцентрировать внимание на занятие, так как у данной категории проявляется рассеянность и не сосредоточенность, они отвлекаются на все что их заинтересует. Очень большое внимание уделялось обучению правильному дыханию, как в первой, так и во второй группе занимающихся. В процессе учебно-тренировочного занятия нами использовались специально-подготовительные упражнения, которые позволяли успешно овладевать отдельными элементами техники плавания «кроль на груди» и «кроль на спине». А также использовали упражнения меньшей интенсивности, выполняли проплывание отрезков по 25 метров в медленном темпе, так как все это обусловлено слабой нервной системой у лиц с нарушением психического развития, а у лиц с поражениями ОДА спецификой заболевания и поражением нижних и верхних конечностей. Отмечалось, что даже небольшие нагрузки вызывали сердцебиение и отдышку, поэтому после проплывания отрезков 25-50 метров выполнялись «выдохи в воду». На протяжение всего года отмечалось, что у занимающихся не так быстро восстанавливаются силы после тренировочного занятия, и им необходимо время на отдых. По окончании тренировочного каждого занятия отдельным занимающимся проговаривалось время и день, когда им необходимо приходить на следующее занятие. В процессе учебно-тренировочных занятий использовался метод «проведение по движению» и «направляющей помощи» [4].

Таблица 1

Прирост показателей уровня физической подготовленности лиц с поражениями ОДА $(n=5)$ до начала и после эксперимента

\begin{tabular}{|c|c|c|c|c|c|c|c|c|c|c|c|c|c|c|}
\hline \multirow{3}{*}{$\begin{array}{c}\text { Виды испытаний } \\
\text { тесты }\end{array}$} & \multicolumn{4}{|c|}{ до эксперимента } & \multicolumn{6}{|c|}{ до эксперимента } & \multirow{2}{*}{\multicolumn{2}{|c|}{$U$}} & \multirow{2}{*}{\multicolumn{2}{|c|}{$\begin{array}{c}\text { Оценка } \\
\text { вероятности }\end{array}$}} \\
\hline & $\mathrm{Me}$ & $25 \%$ & \multicolumn{2}{|c|}{$75 \%$} & \multicolumn{2}{|c|}{$\mathrm{Me}$} & \multicolumn{2}{|c|}{$25 \%$} & \multicolumn{2}{|c|}{$75 \%$} & & & & \\
\hline & \begin{tabular}{l|l|} 
п & л \\
\end{tabular} & \begin{tabular}{|l|l|} 
п & л \\
\end{tabular} & $\Pi$ & л & $\Pi$ & л & $\Pi$ & л & $\Pi$ & л & П & л & $\Pi$ & л \\
\hline $\begin{array}{l}\text { Динамометрия } \\
\text { кистевая, кг }\end{array}$ & \begin{tabular}{l|l}
6,5 & 6
\end{tabular} & \begin{tabular}{l|l|}
5 & 4
\end{tabular} & 8,5 & 7,75 & 7 & 6,65 & 5,5 & 4,5 & 9 & 8,5 & 15 & 17 & $p>0,05$ & $p>0,05$ \\
\hline $\begin{array}{l}\text { Динамометрия } \\
\text { становая, кг }\end{array}$ & 21,6 & 13,3 & & 3,8 & & 2,5 & 15 & & & 9 & & 15 & $p>c$ &, 05 \\
\hline $\begin{array}{l}\text { Модифицированный } \\
\text { тест Купера, м }\end{array}$ & 459,6 & 396,3 & & 3,8 & & 96,6 & 42 & & 5 & 55 & & 20 & $p>$ &, 05 \\
\hline $\begin{array}{l}\text { Прыжок в длину } \\
\text { с места, см }\end{array}$ & 48,5 & 33,2 & & 5,8 & & 4,3 & 4 & & & 0,3 & & 17 & $p>c$ &, 05 \\
\hline Тест на гибкость, см & $-5,7$ & $-12,5$ & & 1 & & -5 & -8 & & & ,5 & & 3 & & 0,05 \\
\hline Проба Ромберга, с & 4 & 3,1 & & 5 & & 4,7 & 3 & & 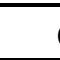 & 6 & & 4 & $p \leq$ & 0,05 \\
\hline
\end{tabular}

Примечание: Ме - медиана; 25 \% - первый квартиль; 75 \% - третий квартиль; $U$-критерий МаннаУитни

Для совершенствования координации движений использовали несложные упражнения. Так как у занимающихся наблюдалась задержка дыхания, то нами применялся на каждом занятии адаптированный комплекс Кифута в сочетании с дыхательными упражнениями. Дыхательные упражнения выполняли в динамике, с выполнением различных упражнений [3, 4].

Как показывает анализ таблицы №1, то прирост по кистевой динамометрии по правой руке составил 7,2\%, по левой 7,7. Прирост становой динамометрии составил 4\%. По модифицированному тесту Купера, отмечается незначительный прирост 7,6\%. Выявлен прирост в тесте «Прыжок в длину с места» на 10,7\%. В тесте на гибкость у занимающихся 
произошли существенные изменения за год и прирост составил 15\%. Прирост в 14,9\% отмечался в пробе Ромберга.

Развитие личности лиц с поражениями ОДА и отклонениями в состоянии здоровья, их физических способностей и познавательной деятельности зависит от основного дефекта, и требует большего времени и различных средств и методов. Формирование движений крупной моторики у занимающихся - один из важнейших компонентов его развития. Чувство радости, ощущение самостоятельности остаются главными источниками мотивации физической активности лиц данной категории [4].

Нарушение отдельных компонентов моторики по-разному влияет на общее психомоторное развитие лиц данного контингента. Коррекция нарушений моторики у лиц с нарушениями интеллекта и умственной отсталости является важным аспектом всей коррекционно-воспитательной работы с ними. Нарушения развития моторики отчетливо заметны при выполнении дифференцированных и точных движений $[1 ; 2]$.

Таблица 2

Прирост показателей уровня физической подготовленности у лиц с нарушениями психических расстройств $(n=5)$ до начала и после эксперимента

\begin{tabular}{|c|c|c|c|c|c|c|c|c|c|c|c|c|c|c|}
\hline \multirow{3}{*}{$\begin{array}{c}\text { Виды испытаний } \\
\text { тесты }\end{array}$} & \multicolumn{4}{|c|}{ до эксперимента } & \multicolumn{6}{|c|}{ до эксперимента } & \multirow{2}{*}{\multicolumn{2}{|c|}{$U$}} & \multirow{2}{*}{\multicolumn{2}{|c|}{$\begin{array}{c}\text { Оценка } \\
\text { вероятности }\end{array}$}} \\
\hline & $\mathrm{Me}$ & $25 \%$ & \multicolumn{2}{|c|}{$75 \%$} & \multicolumn{2}{|c|}{$\mathrm{Me}$} & \multicolumn{2}{|c|}{$25 \%$} & \multicolumn{2}{|c|}{$75 \%$} & & & & \\
\hline & \begin{tabular}{l|l} 
п & л
\end{tabular} & $\Pi$ & $\Pi$ & л & $\Pi$ & л & $\Pi$ & л & $\Pi$ & л & $\Pi$ & л & $\Pi$ & л \\
\hline $\begin{array}{l}\text { Динамометрия } \\
\text { кистевая, кг }\end{array}$ & 77.6 & \begin{tabular}{l|l}
5 & 5,6
\end{tabular} & 9,5 & 9 & 10 & 10,6 & 9,25 & 8,1 & 13 & 12,8 & 1 & 2 & $p>0,05$ & $p>0,05$ \\
\hline $\begin{array}{l}\text { Динамометрия } \\
\text { становая, кг } \\
\end{array}$ & 24,1 & 14,3 & 33, & & & 5,8 & 2 & & & 4,3 & 1 & 1 & & \\
\hline $\begin{array}{l}\text { Модифицированный } \\
\text { тест Купера, м }\end{array}$ & 590 & 526,3 & 636 & & & 0,4 & 596 & & & 15 & 4 & 4 & & \\
\hline $\begin{array}{l}\text { Прыжок в длину } \\
\text { с места, см }\end{array}$ & 100 & 50 & 150 & & & 20 & 7 & & & 70 & 4 & 4 & $p \leq$ & \\
\hline Тест на гибкость, см & 0 & -5 & +5 & & & 35 & + & & & +6 & 1 & & $p \leq$ & 0,05 \\
\hline $\begin{array}{l}\text { Проба } \\
\text { Ромберга, с }\end{array}$ & 5,6 & 3,6 & 7,9 & & & ,6 & 5 , & & & 0,1 & 7 & & &, 05 \\
\hline
\end{tabular}

Примечание: Ме - медиана; 25\% - первый квартиль; 75\% - третий квартиль; U - критерий МаннаУитни

У занимающихся данной категории прирост по кистевой динамометрии по правой руке составил $30 \%$, а по левой $28,4 \%$. Из таблицы 2 видно, что прирост по становой динамометрии составил $32,7 \%$. У занимающихся существенно повысился прирост при выполнении модифицированного теста Купера, и составил $12 \%$. В тесте «прыжок в длину с места» прирост составил 16,7\% [3] При выполнении теста обращали внимание на то как приземляется занимающийся [2]. Прыжки способствуют совершенствованию скорости реакции, координации движений. Прыжки направлены на развитие взрывной силы, ловкости. Поэтому нами были исключены прыжковые упражнения при занятиях занимающимися, имеющих тяжелую форму психических нарушений. Тест на гибкость испытуемые выполнили достаточно хорошо, и прирост составил 71,5\%. Прирост 26,4\% составил в пробе Ромберга.

Сравнительный анализ прироста показателей физической подготовленности у двух групп показал, что прирост по результатам кистевой динамометрии у второй группы составил по левой руке $-22,8 \%$, а по правой руке $-20,7 \%$. По результатам становой динамометрии прирост у второй группы по сравнению с первой составил $28,7 \%$. Все это показывает, что 
первая группа в силу специфичности дефекта не может пока выполнить лучше. По показателям модифицированного теста Купера разница составила 1,3\% в пользу второй группы. Разница показателей теста «прыжок в длину с места» составила 1,7\%. В тесте на гибкость разница составила 56,5\%. Результаты пробы Ромберга показали, что вторая группа выполнила лучше тест, и разница составила 11,5\%. Поэтому наши исследования позволят принимать участие в комплексе ГТО для лиц с нарушениями в развитии [2-4].

Анализ исследования физической подготовленности у лиц с отклонениями в состоянии здоровья показал, что у испытуемых за год произошли существенные изменения в показателях, за счет выполнения различных дыхательных упражнений, общеразвивающих и двигательных заданий. А также педагогические наблюдения, показали, что все испытуемые стали больше двигаться, гулять на улице, играть в подвижные игры с товарищами. Все это способствует формированию адекватной мотивации к занятиям адаптивного плавания, участие в комплексе ГТО среди лиц с ограниченными возможностями в состоянии здоровья.

\section{Литература}

1. Бударин М.В. Методика обучения плаванию детей 11-12 лет с интеллектуальными нарушениями на начальном этапе спортивной подготовки // Культура физическая и здоровье. 2018. № 4(68). С. 142-144.

2. Петрунина С.В., Хабарова С.М. Особенности коррекции и восстановления двигательных функций в водной среде с системой «Регулируемая страховка» //Актуальные проблемы физической культуры, спорта и туризма: Материалы XII межд. науч.-практ. конф. Уфа: РИК УГАТУ, 2018. С. 497-501.

3. Петрунина С.В., Хабарова С.М., Кирюхина И.А. Особенности адаптивного плавания для детей с поражением ОДА // Актуальные проблемы физической культуры и спорта в современных социально-экономических условиях: Материалы Международной науч.-практ. конф. г. Чебоксары, 2020. С. 542-547.

4. Рубцова Н.О., Рубцов А.В. Технологии адаптивного физического воспитания и спортивной подготовки лиц с нарушениями психического развития. 2-е изд., стер. СанктПетербург: Лань, 2021. 208 с.

(C) Петрунина C.B., 2021 